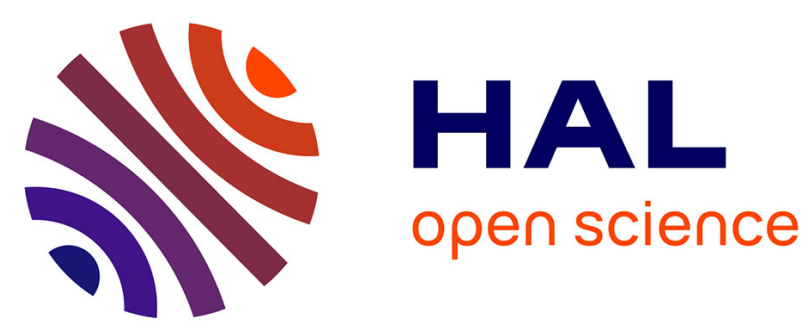

\title{
Ecosystem productivity is associated with bacterial phylogenetic distance in surface marine waters
}

\author{
Pierre E. Galand, Ian Salter, Dimitri Kalenitchenko
}

\section{To cite this version:}

Pierre E. Galand, Ian Salter, Dimitri Kalenitchenko. Ecosystem productivity is associated with bacterial phylogenetic distance in surface marine waters. Molecular Ecology Notes, 2015, 24 (23), pp.57855795 10.1111/mec.13347 . hal-01205185

\section{HAL Id: hal-01205185 \\ https://hal.sorbonne-universite.fr/hal-01205185}

Submitted on 25 Sep 2015

HAL is a multi-disciplinary open access archive for the deposit and dissemination of scientific research documents, whether they are published or not. The documents may come from teaching and research institutions in France or abroad, or from public or private research centers.
L'archive ouverte pluridisciplinaire HAL, est destinée au dépôt et à la diffusion de documents scientifiques de niveau recherche, publiés ou non, émanant des établissements d'enseignement et de recherche français ou étrangers, des laboratoires publics ou privés. 
1 Ecosystem productivity is associated with bacterial phylogenetic distance in surface marine waters

4

Pierre E. Galand ${ }^{1}$, Ian Salter ${ }^{2,3}$, Dimitri Kalenitchenko ${ }^{1}$

${ }^{1}$ Sorbonne Universités, UPMC Univ Paris 06, CNRS, Laboratoire d'Ecogéochimie des

Environnements Benthiques (LECOB), Observatoire Océanologique de Banyuls, F-66650,

Banyuls sur Mer, France

${ }^{2}$ Sorbonne Universités, UPMC Univ Paris 06, CNRS, Laboratoire d'Océanographie

Microbienne (LOMIC), Observatoire Océanologique de Banyuls, F-66650 Banyuls sur Mer,

France

${ }^{3}$ Alfred-Wegener-Institute for Polar and Marine Research, Bremerhaven, Germany

*Correspondence to: Pierre Galand, Observatoire Océanologique de Banyuls, Banyuls sur Mer, France. mail: pierre.galand@obs-banyuls.fr. phone: +33 430192451 


\section{Abstract}

Understanding the link between community diversity and ecosystem function is a fundamental aspect of ecology. Systematic losses in biodiversity are widely acknowledged but the impact this may exert on ecosystem functioning remains ambiguous. There is growing evidence of a positive relationship between species richness and ecosystem productivity for terrestrial macroorganisms, but similar links for marine microorganisms, which help drive global climate, are unclear. Community manipulation experiments show both positive and negative relationships for microbes. These previous studies rely, however, on artificial communities and any links between the full diversity of active bacterial communities in the environment, their phylogenetic relatedness, and ecosystem function remains hitherto unexplored. Here we test the hypothesis that productivity is associated to diversity in the metabolically active fraction of microbial communities. We show in natural assemblages of active bacteria that communities containing more distantly related members were associated with higher bacterial production. The positive phylogenetic diversity-productivity relationship was independent of community diversity calculated as the Shannon index. From our long-term (7-year) survey of surface marine bacterial communities we also found that similarly productive communities had greater phylogenetic similarity to each other, further suggesting that the traits of active bacteria are an important predictor of ecosystem productivity. Our findings demonstrate that the evolutionary history of the active fraction of a microbial community is critical for understanding their role in ecosystem functioning.

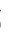

\section{6} 7 (1)

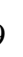




\section{Introduction}

The effect of biodiversity on ecosystem functioning is a key topic in ecology pertaining to the current biodiversity crisis and mounting evidence that biodiversity loss reduces ecosystem function (Cardinale et al. 2012; Naeem et al. 2009). The majority of current research on the biodiversity - ecosystem functioning (BEF) relationship has focused on plants and manipulated plots (Balvanera et al. 2006). Although a positive relationship is generally observed (Cardinale et al. 2012; Gillman \& Wright 2006), negative, U-shaped, and absent relationships have all been reported (Adler et al. 2011; Balvanera et al. 2006; Gillman \& Wright 2006). In the oceans, species richness of macro-organisms appears to enhance ecosystem function (Worm et al. 2006). However, it is widely acknowledged that marine ecosystems represent the largest knowledge gap in BEF studies despite providing a number of key services (Naeem 2012).

In the context of BEF relationships, ecosystem function is a rather generic concept that requires clarification and perhaps distinction from ecosystem services (e.g. (Worm et al. 2006)), the latter representing an anthropocentric viewpoint. For plants, ecosystem function has largely been addressed as productivity (Gillman \& Wright 2006), which accurately reflects their role in structuring ecosystems. Marine bacterial communities, however, mediate a wide range of biogeochemical pathways that contribute to ecosystem function, including but not limited to metabolic balance through respiration (Del Giorgio et al. 1997), nutrient regeneration (Francis et al. 2005; Martens-Habbena et al. 2009) and the production of climatically active gases (Carini et al. 2014; Howard et al. 2008). In the present study we define microbial ecosystem function as heterotrophic production estimated from leucine incorporation (Kirchman et al. 1985). This facilitates a direct comparison with primary production and provides a rate measurement to establish a conceptual framework linking diversity-productivity relationships in heterotrophic bacterial communities. 
Marine bacteria provide significant ecosystem services through the breakdown and mineralization of organic matter, which in turn generates climatically active gases and influences trophic energy transfer. Despite the ecological significance of bacterial processes, the importance of the enormous diversity contained within marine bacterial communities for ecosystem productivity remains ambiguous. BEF research on marine microbes is scarce even though they represent good community models to test ecological theory and often follow ecological patterns similar to macroorganisms (Fuhrman 2009; Martiny et al. 2006). The BEF relationship for microbes is hypothesised to represent the form of a saturating curve (Naeem 2012) and initial experiments based on artificial communities do display positive relationships (Bell et al. 2005; Gravel et al. 2011; Hodgson et al. 2002). However, contrasting results show a negative or no relationship between bacterial richness and productivity in both the natural environment (Obernosterer et al. 2010; Reinthaler et al. 2005) and controlled experimental settings (Becker et al. 2012; Horner- Devine et al. 2003). The ambiguity of these findings may reflect a number of confounding factors including evolutionary history (Gravel et al. 2011) or the dominance effect (Hodgson et al. 2002), which says that more diverse communities are more likely to harbour highly productive species.

Phylogenetic diversity can be considered as a measure of the ecological differences between species (Cavender- Bares et al. 2009; Mouquet et al. 2012) and is also a good predictor of ecosystem productivity (Cadotte 2013; Cadotte et al. 2008; Gravel et al. 2012). However, in order to use phylogenetic diversity to predict ecological function a number of key assumptions should be respected. These assumptions have been recently reviewed and the use of phylogenetic diversity in ecosystem function studies was critically re-examined (Narwani et al. 2015). Nevertheless, phylogenetic diversity has recently been proposed as a better index than richness for conservation policy because it takes into account the evolutionary uniqueness of a species, and phylogenetic based conservation can help 
maintaining a better ecosystem functioning (Mouquet et al. 2012; Rolland et al. 2012). In studies of ecology the use of evolutionary information could be a good alternative to traitbased approaches of the BEF relationship, which include the phenotypic characteristics of individuals that impact their fitness (Mouquet et al. 2012; Srivastava et al. 2012). Including estimates of community trait or evolutionary information may help to disentangle the two main drivers of the BEF relationship: the complementary effect, for which high diversity communities efficiently use resources through positive interactions and/or niche partitioning, versus the selection or sampling effect, whereby diverse community are more likely to contain highly productive organisms (Loreau \& Hector 2001). In artificial microbial communities a positive relationship between phylogenetic distance and productivity (Jousset et al. 2011; Venail \& Vives 2013) disappears under certain evolutionary conditions (Gravel et al. 2012). In the present study we use a long-term microbial time-series from Mediterranean surface waters (MOLA, Microbial Observatory of Laboratoire Arago) to test the hypotheses that (i) productivity is associated to diversity in the metabolically active fraction of bacterial communities and (ii) phylogenetic diversity is a better predictor of bacterial productivity than comparative measures of community diversity. The basis of our hypotheses reflects two fundamental facets of microbial ecosystems. First, a significant fraction of microbial diversity may be present as inactive or dormant cells (Lennon and Jones 2011), thereby limiting their contribution to ecosystem function. Active and inactive microbial communities have also been shown to have different phylogenetic structure (DeAngelis \& Firestone 2012). Second, the breakdown of complex organic substrates relies on complementary microbial consortia possessing a wide range of traits. Addressing these questions with natural bacterial communities should negate any uncertainties associated to artificial selection of bacteria grown on culture media. Further, the use of data obtained from a microbial observatory provides a robust framework for the study, as repeated measures from a single location 
strongly limits possible bias associated to fluctuating conditions in nature. Pyrosequencing of the $16 \mathrm{~S}$ ribosomal RNA genes and $16 \mathrm{~S}$ ribosomal RNA was carried out to compare the entire bacterial assemblage, referred to as "standing stock", to the "active fraction". Parallel to measurements of phylogenetic structure within bacterial communities, the incorporation of tritiated-leucine was used as a direct rate estimate of community productivity.

\section{Materials and Methods}

\section{Sample collection}

Seawater was collected at approximately monthly resolution from July 2004 to April 2011 at 3-5 m depth at the MOLA (Microbial Observatory of Laboratoire Arago) station off Banyuls sur Mer $\left(42^{\circ} 27^{\prime} 205 \mathrm{~N}-03^{\circ} 32^{\prime} 565 \mathrm{E}\right)$. Occasionally samples were not collected due to poor weather conditions. A subset of 41 field samples were selected for the diversity/production comparison, as production was not always measured during the course of the MOLA monitoring. Seasonal patterns of community similarity and environmental conditions were followed on 57 samples. As described earlier (Salter et al. 2015), the water sampled with a 12-L Niskin bottle was kept in 10-L high-density polyethylene carboys in the dark until being processed in the laboratory (within $1.5 \mathrm{~h}$ ). The microbial biomass was collected on $0.22-\mu \mathrm{m}$ pore-size GV Sterivex cartridges (Millipore) from $10 \mathrm{~L}$ of seawater after prefiltartion through $3-\mu \mathrm{m}$ pore-size polycarbonate filters (Millipore). Filters were stored at $-80{ }^{\circ} \mathrm{C}$ until nucleic acid extraction. In-situ temperature and salinity were obtained using a Seabird CTD SBE9/11. Chlorophyll a concentrations were measured from one liter of seawater collected on a GF/F filter at low pressure $(<0.2$ bar). Following filtration, samples were processed immediately or stored at $-20^{\circ} \mathrm{C}$ for a period $<1$ week. Upon processing, samples were soaked in $90 \%$ acetone at $4{ }^{\circ} \mathrm{C}$ for a period of approximately $12-16 \mathrm{~h}$ and processed within $2 \mathrm{~h}$. Filters were soaked in 
acetone for $24 \mathrm{~h}$ at $4{ }^{\circ} \mathrm{C}$. Fluorescence was measured before and after acidification to correct for phaeopigments.

\section{Bacterial production}

Bacterial production was determined by $3 \mathrm{H}$-leucine incorporation using the centrifugation method (Smith \& Azam 1992). Subsamples (1.5 mL; three replicates and two blanks killed with $50 \%$ of trichloracetic acid (TCA)) were incubated for $2 \mathrm{~h}$ in the dark at in situ temperature with a mixture of ${ }^{3} \mathrm{H}$-leucine (Perkin Elmer, (SA) $115.4 \mathrm{Ci} \mathrm{mmol}^{-1}$ ) and nonradioactive leucine at final concentrations of 7 and $13 \mathrm{nM}$, respectively. Incubations were stopped by the addition of TCA to a final concentration of 5\%. After a centrifugation at $13,300 \mathrm{Xg}$ for $15 \mathrm{~min}$, the supernatant was discarded, and $0.5 \mathrm{~mL}$ of $5 \% \mathrm{TCA}$ were added. This step was applied twice with a second centrifugation for $5 \mathrm{~min}$. Ethanol $(0.5 \mathrm{~mL}$ of $70 \%)$ were added prior to the last centrifugation for $5 \mathrm{~min}$. The supernatant was discarded, and 1 $\mathrm{mL}$ of PCS liquid scintillation cocktail was added. The radioactivity incorporated into bacterial cells was measured with a LS 6500 Beckman liquid scintillation counter.

\section{Nucleic acid extraction and pyrosequencing}

The present study relies on the sequence data originally published in the study by Salter and colleagues (2015). The nucleic acid extraction method followed (Hugoni et al. 2013) and consisted of cell lysis with freshly prepared lysozyme solution $\left(20 \mathrm{mg} \mathrm{mL}^{-1} 1\right)$ applied directly to Sterivex cartridges, and a second incubation after adding proteinase $\mathrm{K}\left(20 \mathrm{mg} \mathrm{mL}^{-1}\right)$, followed by extraction using the AllPrep DNA/RNA kit (Qiagen), which gave average DNA concentrations of $28 \mathrm{ng} \mu \mathrm{L}^{-1}$. The RNA samples were tested for the presence of contaminating genomic DNA by PCR and then reverse-transcribed with random primers using the SuperScript III Reverse Transcriptase kit (Invitrogen). The amplification of the V1-V3 region 
of the 16S rRNA gene was performed by a commercial laboratory (Research and Testing Laboratory, Lubbock, TX) with universal bacterial primers 28F (TTTGATCNTGGCTCAG) and 519R (GTNTTACNGCGGCKGCTG), followed by pyrosequencing using a Roche 454 GS-FLX system with titanium chemistry. All sequences have been submitted to the sequence read archive (SRA) under the Bioproject accession number: PRJNA235253 (Salter et al. 2015).

\section{Sequence data analyses}

Sequences were analyzed as described earlier (Blanquer et al. 2013). Briefly, sequences were first filtered by removing low quality reads, then trimmed to remove reads having $\geq 3 \%$ of bases with Phred values $<27$ ( $0.2 \%$ per-base error probability). This is recommended to ensure that when clustering at 97\%, the influence of erroneous reads is minimized (Huse et al. 2010). Sequences were then clustered at a $97 \%$ threshold using the Uclust algorithm (Edgar 2010). Sequences from each OTU were classified by comparison to the Greengenes database (DeSantis et al. 2006). Sequence analyses were conducted with Pyrotagger (Kunin \& Hugenholtz 2010). Sequences affiliated to chloroplasts were removed but cyanobacterial sequences were kept. For diversity analysis, all samples were randomly re-sampled to the size of the sample containing fewest sequences $(\mathrm{n}=446)$ using Daisy Chopper (Gilbert $e t$ al. 2009). Resampling allows a comparison of bacterial communities without bias associated to varying sampling size.

\section{Diversity measures}

The Shannon diversity index $(\mathrm{H})$ was calculated using the software PAST v2.17 (Hammer $e t$ al. 2001). In the calculation of phylogenetic diversity, $300 \mathrm{bp}$ long representative sequences for each OTU were aligned using MUSCLE (Edgar 2004) and the alignment was then cleaned 
to remove non overlapping sequence regions. A phylogenetic tree was constructed using FastTree (Price et al. 2010).

Phylogenetic diversity (PD) (Faith 1992) is the most common measure of phylogenetic diversity but since the number of taxa in a sample affects PD, and because the number of taxa varied significantly between our samples, we computed a standardized measure of phylogenetic diversity. The standardized effect size (SES) of the phylogenetic diversity is equivalent to -1 times the Nearest Relative Index (NRI) (Webb et al. 2002). It was calculated as:

$$
S E S_{M P D}=\frac{M P D_{\text {observed }}-\text { mean }\left(M P D_{\text {randomizations }}\right)}{s d\left(M P D_{\text {randomizations }}\right)}
$$

where MPD is the mean pairwise phylogenetic distance among taxa within a community weighted by taxa abundance (Webb et al. 2008). We chose to weight MPD by taxa abundance to account for the structure of environmental marine bacteria communities, which are characterized few abundant taxa and a very large number of rare taxa. The observed phylogenetic diversity is compared to the average (mean) phylogenetic diversity in a randomly generated community (null model) and divided by the standard deviation (sd) of phylogenetic distances in the null model. The null model randomizes community data matrix with the independent swap algorithm maintaining species occurrence frequency and sample species richness (Kembel 2009). For comparison, we also computed the unweighted MPD. Positive SES values indicate greater phylogenetic distance among co-occurring species than expected by chance while negative values indicate small phylogenetic distance. Phylogenetic diversity was computed using the Picante package (Kembel et al. 2010) in R.

\section{Statistics}


Linear relationships between productivity and diversity were tested using ordinary least squares regression (OLS) models and the statistical significance of models described with $\mathrm{F}$ statistics. All statistical computations were performed in R. A Breusch-Pagan test for heteroskedasticity was conducted on the residuals to verify that the assumption of homoscedasticity was met, and residuals were tested for normality by examining the quantiles of a standard normal distribution against the corresponding quantiles of the observed data (QQ plot). The most homoscedastic and normally distributed residuals were found in linear models using a log transformation of bacterial production. If linear models were not significant polynomial quadratic functions were tested to detect possible curvilinear relationships. Productivity-diversity relationships were considered to be non-significant when model fits to either linear or curvilinear regressions were not significant.

In order to test if there was a correlation between the phylogenetic structure of a community and the level of bacterial production we measured the phylogenetic distance between each community (sample) by quantifying the mean phylogenetic distance between each OTU in one community and its closest relative in a second community. Distances were computed using $\mathrm{R}$ with the comdistnt function of the picante package (Webb et al. 2008). Similarly, to measure similarity between community composition (beta diversity) and bacterial production we also calculated the Bray-Curtis index based on abundance data and the Sorensen index based on presence-absence data. Differences in bacterial heterotrophic production between communities were calculated as a Euclidian distance. A mantel test (999 permutations) was used to determine whether community composition similarity followed differences in bacterial production.

We use canonical correspondence analysis (CCA) to explore the relationship between community composition and the following environmental parameters: salinity, chlorophyll a, nitrate, nitrite, ammonium, phosphate and silicate. The community data matrices were 
converted using a Hellinger transformation prior to analysis and environmental data were log transformed (Legendre \& Gallagher 2001). The significance of the CCA results was tested by permutation test. Analyses were conducted in $\mathrm{R}$ with the vegan package.

In order to detect possible seasonal patterns in bacterial community composition we carried out an autocorrelation analysis to look at the similarity between Bray-Curtis values, calculated between each bacterial communities, as a function of time, in number of days, which separates two samples. The Lomb periodogram algorithm implemented in Past v2.17 (Hammer et al. 2001) was used to detect if there were seasonal patterns of community diversity and to identify the frequency of the pattern when detected.

\section{Results}

A total of 66705 16S rDNA and 57524 rRNA sequences were obtained after performing quality filtering and yielded a total of 2222 OTUs. SAR11 sequences were the most abundant, with an average contribution of 78 and $45 \%$ in the rDNA and rRNA fractions, followed by Cyanobacteria. The detailed seasonal patterns are described in Salter et al. 2015. Overall, the oligotrophic Northwestern Mediterranean was characterized by a marked seasonality with a peak of bacterial production that closely succeeded chlorophyll a maxima and preceded temperature maxima. In winter, microbes from deeper layers were introduced to surface waters (Figure 1).

Through the analysis of a seven year monthly time-series of surface bacterial communities we observed no linear and no unimodal (quadratic) relationship between the diversity of active bacteria communities, calculated as the Shannon index, and bacterial production $\left(\mathrm{F}_{1,39}=0.60, \mathrm{P}=0.44\right)$ (Figure $\left.2 \mathrm{a}\right)$. Considering different metrics of diversity, like OTU richness, did not influence the results (Figure S1a, Table S1). In contrast, the phylogenetic diversity of the active communities, calculated as average observed 
phylogenetic diversity between taxa, was positively correlated to bacterial production $\left(\mathrm{F}_{1,39}=10.86, \mathrm{P}=0.003\right)$ (Figure $2 \mathrm{~b}$, Table $\left.\mathrm{S} 1\right)$. When phylogenetic diversity was not weighted by taxa abundance, there was no relationship between production and phylogenetic diversity (Figure S2).

The diversity (Shannon's index) of the standing stock was negatively correlated to bacterial production $\left(\mathrm{F}_{1,44}=13.87, \mathrm{P}<0.01\right)$ (Figure $\left.2 \mathrm{c}\right)$ and the phylogenetic diversity was not associated to bacterial production (Figure 2d).

We also investigated if active community composition was related to ecosystem productivity and found a positive relationship between difference in bacterial production and phylogenetic distance between active communities (r-Mantel=0.24, $\mathrm{P}<0.01)$ (Figure 3a). The similarity in community composition of the active fraction, calculated as the Bray-Curtis or Sorensen index, was also associated to differences in bacterial production (r-Mantel=0.34, $\mathrm{P}<0.01$ )(Figure S3). The association did not hold for the standing stock of Bacteria (Figure $3 b)$.

We examined how predictable the bacterial community composition was from year to year in the surface Mediterranean Sea by calculating a Bray-Curtis distance between each pair of samples and then conducting an autocorrelation analysis (Fig. 4a, c). For the active fraction (rRNA), we observed a highly reproducible seasonal composition. Samples taken one year apart had the most similar community composition, shown by the highest correlation values, and communities separated by 6 months were the most different as shown by the lowest correlation values (Figure 4a). Inversely, the standing stock (rRNA gene copies) patterns of high and low correlation values didn't have a significant regular frequency, which indicates that communities did not exhibit regular patterns of community similarity (Figure 4c). As for community diversity, the active fraction did not show a significant regular seasonal pattern (Figure 4b) while the standing stock did (Figure 4d, Figure S4). 
Finally, overall, active bacteria appear to have a stronger association to environmental conditions than the standing stock (Table S2).

\section{Discussion}

The linear increase of productivity with phylogenetic diversity (Figure 2) suggests that assemblages containing more distantly related species are associated to higher community productivity, maybe through more efficient utilization of growth resources. Assuming that trait dissimilarity is correlated with evolutionary time (Cadotte et al. 2009; Connolly et al. 2011), bacteria with distant common ancestors are more likely to be ecologically different. Through competitive exclusion any such ecological differentiation would promote distinct species, or groupings of species with reduced niche overlap (e.g. (Spehn et al. 2005; Tilman et al. 2001)) that can utilize a wide range of substrates associated with enhanced community productivity. Our findings from a natural environment adds to recent reports from artificial bacterial communities showing that higher functional dissimilarity can increase ecosystem functioning through a better use of resources, especially in complex resource environments (Jousset et al. 2011; Venail \& Vives 2013). Alternatively, a phylogenetically diverse community may reflect functional complementarity between species collaborating for an efficient use of resources (Cavender- Bares et al. 2009). Our data did not help us separate these hypotheses as we could not specifically identify taxa always associated to high phylogenetic diversity scenarios (not shown). Nevertheless, such positive interactions are especially relevant for microbial communities in which substrates are often used through a cascade of commensal or mutualistic organisms and consumption of secondary metabolites. Alternatively to these two hypotheses, the causation could go the other direction and more productive communities may select for bacteria that are more phylogenetically diverse. 
In the oligotrophic Northwestern Mediterranean, the peak of heterotrophic bacterial

production closely succeeds chlorophyll a maxima and precedes temperature maxima, indicating that substrates derived from the decaying phytoplankton promote high levels of community productivity (Figure 1). The production of a wide range of organic carbon substrates from zooplankton grazing and phytoplankton lysis (e.g. (Van Wambeke 1994)) may be the initial trigger for facilitating the development of a phylogenetically diverse assemblage. The presence of diverse assemblages would fit the recent genome streamlining theory, which suggests a more efficient use of nutrients in microbial communities composed of different but highly connected microorganisms (Giovannoni et al. 2014). Many microbial pathways may leak metabolites that can escape the cell and become available to other members of the community (Morris et al. 2012). The prevalence of genome streamlining in the oceans together with specialization in resource utilization (Swan et al. 2013) are additional arguments for the presence of interdependent microorganisms within marine communities.

In turn, the negative phylogenetic diversity values associated to low productivity times can be interpreted as communities structured by environmental filtering. The environment selects a subset of ecologically similar taxa able to thrive under specific environmental conditions. In the Northwestern Mediterranean, such filter could be the lower winter temperature, the higher nitrogen availability or other factors that we did not measure. However, the temporal resolution (monthly) of our observations within a natural ecosystem renders it challenging to identify mechanisms of causality between phylogenetic diversity and productivity.

Another important ecological question is whether the relationship between phylogenetic diversity and community production is due to a strong co-variation with community richness (Mouquet et al. 2012). Co-variation is not supported by our data showing 
that bacterial assemblage diversity was not correlated to productivity (Figure 2). In contrast, manipulation experiments frequently describe positive relationships between diversity and productivity (Bell et al. 2005; Gravel et al. 2011; Hodgson et al. 2002). We infer that the biodiversity - ecosystem functioning (BEF) relationship observed in a natural system is influenced by complex interactions taking place between individuals and environmental factors that cannot be accurately reproduced using artificial communities in a laboratory setting. The unique effect of phylogenetic diversity suggests that increased productivity can be explained by complementary rather than sampling effect. Sampling a deep branching or a clustered community, at similar richness level, would in theory result in a similar probability of sampling more productive taxa.

The positive relationship between differences in bacterial production and phylogenetic distance between communities (Figure 3) indicates that similar assemblages of active bacteria are associated to comparable levels of community production, and specifically that the communities that were the most different had distinct productivity levels. In support of our other findings these results show that the identity of the active bacteria composing bacterial assemblages, and consequently the ecological traits of individuals rather than community diversity, is essential for predicting productivity. Reports of relationships between community composition and ecosystem function for natural bacterial communities are rare. They show only weak or no coupling between communities and ecosystem function, thus implying a certain degree of functional redundancy (Frossard et al. 2011; Langenheder et al. 2005). Opposingly, based on our findings of a highly reproducible seasonal composition of active communities we argue that active bacterial communities in a defined ecosystem exhibit little functional redundancy and that the non-active members of a community (e.g. standing stock) mask the relationship between composition and function. Active bacteria appear to have a stronger association to biogeochemical forcing than the standing stock further suggesting that 
ecosystem productivity is associated to a specific pool of active bacteria that could respond predictably to seasonality in environmental conditions.

It should be noted that there is still some ambiguity as to whether $16 \mathrm{~S}$ rRNA is a reliable metric of metabolically active cells. The correlation between rRNA copy number and real time activity can be inconsistent in environmental samples and rRNA has been suggested to represent a protein synthesis potential rather than a direct indicator of metabolic state (Blazewicz et al. 2013). Our previous work on the MOLA microbial Observatory data shows, however, a correlation between SAR11 RNA/DNA ratio and single cell activity measured by fluorescence in-situ hybridisation coupled with microautoradiography (MICRO-CARD-FISH) (Salter et al. 2015). It supports the idea that RNA sequence data might be a useful metric for tracking the general metabolic activity of these communities.

Contrary to our observations on active bacteria, the diversity of the standing stock was negatively correlated to bacterial production. In the surface waters of the Mediterranean this negative relationship reflects a physical process with significant ecological consequences. In winter, wind-induced breakdown of water column stratification introduces microbes from deeper layers (Salter et al. 2015). This seasonal vertical mixing occurs each year and although it enhances diversity of the standing stock, as deep Bacteria are probably not active at the surface, it does not result in a predictable community composition or a systematic increase in diversity of active bacterial communities. This result from our off shore Mediterranean site contrasts with earlier reports of strongly predictable patterns of bacterial community composition (Chow et al. 2013; Fuhrman et al. 2006).

The contrasting patterns of standing stock and active communities reflect the specificity of microbial communities that are frequently composed of inactive organisms able to survive long periods of with reduced activity or in a dormant stage (Lennon \& Jones 2011). We argue that the existence of a large number of microorganisms that don't contribute to 
ecosystem productivity underpins a fundamental dichotomy between micro- and macroecology. These features of microbial community diversity and productivity need to be taken into account when using microbes as model communities and transferring ecological theories to microorganisms.

In summary, our results present strong support for a positive relationship between phylogenetic diversity, independent of community diversity, and productivity in natural communities, and stress the importance of community structure for predicting ecosystem function. We also emphasize that the community diversity-productivity relationship observed for the standing stock of bacteria was different from the one expressed by the active fraction, and argue that active microorganisms need to be targeted in ecological studies, especially in dynamic ecosystems, for an unbiased comparison of micro- and macro-ecology. Using this approach in the future should lead to a better understanding of oscillations in the ocean services provided by marine microbial communities and improve the predictive capacity of models linking environmental and anthropogenic change to community diversity and productivity.

\section{Acknowledgments}

The work of P.E.G. was supported by the Agence Nationale de la Recherche (ANR) through the projects MICADO (ANR-11-JSV7-003-01) and EUREKA (ANR-14-CE02-0004-01). I.S. was jointly supported by a LEFE-CYBER grant and LOMIC 500 micro-project grant. We thank Cyrielle Tricoire, Eric Maria and Louise Oriol for assisting with the collection and analysis of samples for the physical and chemical parameters over the time-series. We extend our acknowledgments to all the researchers that were involved in working with the time-series over the years. 


\section{References}

Adler PB, Seabloom EW, Borer ET, et al. (2011) Productivity is a poor predictor of plant species richness. Science, 333, 1750-1753.

Balvanera P, Pfisterer AB, Buchmann N, et al. (2006) Quantifying the evidence for biodiversity effects on ecosystem functioning and services. Ecology Letters, 9, 1146-1156.

Becker J, Eisenhauer N, Scheu S, Jousset A (2012) Increasing antagonistic interactions cause bacterial communities to collapse at high diversity. Ecology Letters, 15, 468-474.

Bell T, Newman JA, Silverman BW, Turner SL, Lilley AK (2005) The contribution of species richness and composition to bacterial services. Nature, 436, 1157-1160.

Blanquer A, Uriz MJ, Galand PE (2013) Removing environmental sources of variation to gain insight on symbionts vs. transient microbes in High and Low Microbial Abundance sponges. Environmental Microbiology, 15, 3008-3019.

Blazewicz SJ, Barnard RL, Daly RA, Firestone MK (2013) Evaluating rRNA as an indicator of microbial activity in environmental communities: limitations and uses. ISME Journal, 7, 2061-2068.

Cadotte MW (2013) Experimental evidence that evolutionarily diverse assemblages result in higher productivity. Proceedings of the National Academy of Sciences of the United States of America, 110, 8996-9000.

Cadotte MW, Cardinale BJ, Oakley TH (2008) Evolutionary history and the effect of biodiversity on plant productivity. Proceedings of the National Academy of Sciences of the United States of America, 105, 17012-17017.

Cadotte MW, Cavender-Bares J, Tilman D, Oakley TH (2009) Using phylogenetic, functional and trait diversity to understand patterns of plant community productivity. PLOS ONE, 4, e5695.

Cardinale BJ, Duffy JE, Gonzalez A, et al. (2012) Biodiversity loss and its impact on humanity. Nature, 486, 5967.

Carini P, White AE, Campbell EO, Giovannoni SJ (2014) Methane production by phosphate-starved SAR11 chemoheterotrophic marine bacteria. Nature communications, $\mathbf{5}$.

Cavender- Bares J, Kozak KH, Fine PV, Kembel SW (2009) The merging of community ecology and phylogenetic biology. Ecology Letters, 12, 693-715.

Chow C-ET, Sachdeva R, Cram JA, et al. (2013) Temporal variability and coherence of euphotic zone bacterial communities over a decade in the Southern California Bight. The ISME journal, 7, 2259-2273.

Connolly J, Cadotte MW, Brophy C, et al. (2011) Phylogenetically diverse grasslands are associated with pairwise interspecific processes that increase biomass. Ecology, 92, 1385-1392.

DeAngelis KM, Firestone MK (2012) Phylogenetic clustering of soil microbial communities by 16S rRNA but not 16S rRNA genes. Applied and Environmental Microbiology, 78, 2459-2461.

Del Giorgio PA, Cole JJ, Cimbleris A (1997) Respiration rates in bacteria exceed phytoplankton production in unproductive aquatic systems. Nature, 385, 148-151.

DeSantis TZ, Hugenholtz P, Larsen N, et al. (2006) Greengenes, a chimera-checked 16S rRNA gene database and workbench compatible with ARB. Applied and Environmental Microbiology, 72, 5069-5072.

Edgar RC (2004) MUSCLE: a multiple sequence alignment method with reduced time and space complexity. BMC Bioinformatics, 5, 113.

Edgar RC (2010) Search and clustering orders of magnitude faster than BLAST. Bioinformatics, 26, $2460-2461$.

Faith DP (1992) Conservation evaluation and phylogenetic diversity. Biological Conservation, 61, 1-10.

Francis CA, Roberts KJ, Beman JM, Santoro AE, Oakley BB (2005) Ubiquity and diversity of ammoniaoxidizing archaea in water columns and sediments of the ocean. Proceedings of the National Academy of Sciences of the United States of America, 102, 14683-14688.

Frossard A, Gerull L, Mutz M, Gessner MO (2011) Disconnect of microbial structure and function: enzyme activities and bacterial communities in nascent stream corridors. The ISME journal, 6, 680-691.

Fuhrman JA (2009) Microbial community structure and its functional implications. Nature, 459, 193-199.

Fuhrman JA, Hewson I, Schwalbach MS, et al. (2006) Annually reoccurring bacterial communities are predictable from ocean conditions. Proceedings of the National Academy of Sciences of the United States of America, 103, 13104-13109.

Gilbert JA, Field D, Swift P, et al. (2009) The seasonal structure of microbial communities in the Western English Channel. Environmental Microbiology, 11, 3132-3139.

Gillman LN, Wright SD (2006) The influence of productivity on the species richness of plants: a critical assessment. Ecology, 87, 1234-1243.

Giovannoni SJ, Cameron Thrash J, Temperton B (2014) Implications of streamlining theory for microbial ecology. ISME J, 8, 1553-1565.

Gravel D, Bell T, Barbera C, et al. (2011) Experimental niche evolution alters the strength of the diversityproductivity relationship. Nature, 469, 89-92. 
Gravel D, Bell T, Barbera C, et al. (2012) Phylogenetic constraints on ecosystem functioning. Nature communications, 3, 1117.

Hammer Ø, Harper DAT, Ryan PD (2001) PAST: Paleontological statistics software package for education and data analysis. Palaeontologia Electronica, 4, 9.

Hodgson DJ, Rainey PB, Buckling A (2002) Mechanisms linking diversity, productivity and invasibility in experimental bacterial communities. Proceedings of the Royal Society B: Biological Sciences, 269, 2277-2283.

Horner- Devine MC, Leibold MA, Smith VH, Bohannan BJ (2003) Bacterial diversity patterns along a gradient of primary productivity. Ecology Letters, 6, 613-622.

Howard EC, Sun S, Biers EJ, Moran MA (2008) Abundant and diverse bacteria involved in DMSP degradation in marine surface waters. Environmental Microbiology, 10, 2397-2410.

Hugoni M, Taib N, Debroas D, et al. (2013) Structure of the rare archaeal biosphere and seasonal dynamics of active ecotypes in surface coastal waters. Proceedings of the National Academy of Sciences of the United States of America, 110, 6004-6009.

Huse SM, Welch DM, Morrison HG, Sogin ML (2010) Ironing out the wrinkles in the rare biosphere through improved OTU clustering. Environmental Microbiology, 12, 1889-1898.

Jousset A, Schmid B, Scheu S, Eisenhauer N (2011) Genotypic richness and dissimilarity opposingly affect ecosystem functioning. Ecology Letters, 14, 537-545.

Kembel SW (2009) Disentangling niche and neutral influences on community assembly: assessing the performance of community phylogenetic structure tests. Ecology Letters, 12, 949-960.

Kembel SW, Cowan PD, Helmus MR, et al. (2010) Picante: R tools for integrating phylogenies and ecology. Bioinformatics, 26, 1463-1464.

Kirchman D, K'nees E, Hodson R (1985) Leucine incorporation and its potential as a measure of protein synthesis by bacteria in natural aquatic systems. Applied and Environmental Microbiology, 49, 599607.

Kunin V, Hugenholtz P (2010) PyroTagger: A fast, accurate pipeline for analysis of rRNA amplicon pyrosequence data. The Open Journal, 1.

Langenheder S, Lindström ES, Tranvik LJ (2005) Weak coupling between community composition and functioning of aquatic bacteria. Limnology and Oceanography, 50, 957-967.

Legendre P, Gallagher ED (2001) Ecologically meaningful transformations for ordination of species data. Oecologia, 129, 271-280.

Lennon JT, Jones SE (2011) Microbial seed banks: the ecological and evolutionary implications of dormancy. Nature Reviews Microbiology, 9, 119-130.

Loreau M, Hector A (2001) Partitioning selection and complementarity in biodiversity experiments. Nature, 412, $72-76$.

Martens-Habbena W, Berube PM, Urakawa H, de La Torre JR, Stahl DA (2009) Ammonia oxidation kinetics determine niche separation of nitrifying Archaea and Bacteria. Nature, 461, 976-979.

Martiny JBH, Bohannan BJM, Brown JH, et al. (2006) Microbial biogeography: putting microorganisms on the map. Nature Reviews Microbiology, 4, 102.

Morris JJ, Lenski RE, Zinser ER (2012) The Black Queen Hypothesis: Evolution of Dependencies through Adaptive Gene Loss. mBio, 3.

Mouquet N, Devictor V, Meynard CN, et al. (2012) Ecophylogenetics: advances and perspectives. Biological reviews, 87, 769-785.

Naeem S (2012) Ecological consequences of declining biodiversity: a biodiversity-ecosystem function (BEF) framework for marine systems. In: Marine Biodiversity and Ecosystem Functioning: Frameworks, methodologies, and integration (eds. Solan M, Aspden RJ, Paterson DM), p. 256. Oxford University Press, Oxford.

Naeem S, Bunker DE, Hector A, Loreau M, Perrings C (2009) Biodiversity, ecosystem functioning, and human wellbeing. An ecological and economic perspective. Oxford University Press, Oxford.

Narwani A, Matthews B, Fox J, Venail P (2015) Using phylogenetics in community assembly and ecosystem functioning research. Functional Ecology, 29, 589-591.

Obernosterer I, Lami R, Larcher M, et al. (2010) Linkage between bacterial carbon processing and the structure of the active bacterial community at a coastal site in the NW Mediterranean Sea. Microbial Ecology, 59, 428-435.

Price MN, Dehal PS, Arkin AP (2010) FastTree 2-approximately maximum-likelihood trees for large alignments. PLoS ONE, 5, e9490.

Reinthaler T, Winter C, Herndl GJ (2005) Relationship between bacterioplankton richness, respiration, and production in the southern North Sea. Applied and Environmental Microbiology, 71, 2260-2266.

Rolland J, Cadotte MW, Davies J, et al. (2012) Using phylogenies in conservation: new perspectives. Biology Letters, 8, 692-694. 
Salter I, Galand PE, Fagervold SK, et al. (2015) Seasonal dynamics of active SAR11 ecotypes in the oligotrophic Northwest Mediterranean Sea. ISME Journal, 9, 347-360.

Smith DC, Azam F (1992) A simple, economical method for measuring bacterial protein synthesis rates in seawater using 3H-leucine. Marine Microbial Food Webs, 6, 107-114.

Spehn E, Hector A, Joshi J, et al. (2005) Ecosystem effects of biodiversity manipulations in European grasslands. Ecological Monographs, 75, 37-63.

Srivastava DS, Cadotte MW, MacDonald AAM, Marushia RG, Mirotchnick N (2012) Phylogenetic diversity and the functioning of ecosystems. Ecology Letters, 15, 637-648.

Swan BK, Tupper B, Sczyrba A, et al. (2013) Prevalent genome streamlining and latitudinal divergence of planktonic bacteria in the surface ocean. Proceedings of the National Academy of Sciences, 110, 1146311468.

Tilman D, Reich PB, Knops J, et al. (2001) Diversity and productivity in a long-term grassland experiment. Science, 294, 843-845.

Van Wambeke F (1994) Influence of phytoplankton lysis or grazing on bacterial metabolism and trophic relationships. Microbial Ecology, 27, 143-158.

Venail PA, Vives MJ (2013) Phylogenetic distance and species richness interactively affect the productivity of bacterial communities. Ecology, 94, 2529-2536.

Webb CO, Ackerly DD, Kembel SW (2008) Phylocom: software for the analysis of phylogenetic community structure and trait evolution. Bioinformatics, 24.

Webb CO, Ackerly DD, McPeek MA, Donoghue MJ (2002) Phylogenies and Community Ecology. Annual Review of Ecology and Systematics, 33, 475-505.

Worm B, Barbier EB, Beaumont N, et al. (2006) Impacts of biodiversity loss on ocean ecosystem services. Science, 314, 787-790.

\section{Data Accessibility:}

DNA sequences: NCBI SRA PRJNA235253

Final OTU table, alignment file, tree file, environmental data and phylogenetic distance matrix: Dryad: doi:10.5061/dryad.dh3st

Author Contributions: P.E.G and I.S. designed the study and wrote the paper. P.E.G. and
D.K. analysed data. All authors discussed the results and commented on the manuscript. 


\section{Figure legends}

Figure 1. Average values and standard errors for environmental data. Nitrate, Chlorophyll a (Chl a), temperature, bacterial production (BP, leucine incorporation) and deep bacteria (expressed as number of SAR202 and SAR406 sequences) presented by month during the seven years survey.

Figure 2. Relationship between bacterial production and the community and phylogenetic diversity of active bacteria (RNA, upper panel) and standing stock (DNA, lower panel). Bacterial production is measured as the rate of tritiated-leucine incorporation ( $p m o l ~ \mathrm{~L}^{-1} \mathrm{~h}^{-1}$ ) and plotted following logarithmic transformation. Community diversity $(\mathrm{a}, \mathrm{c})$ is expressed as the Shannon diversity index and phylogenetic diversity $(b, d)$ as standardized effect size (SES) of the phylogenetic diversity. SES corresponds to the average observed phylogenetic diversity in a community compared to the average phylogenetic diversity in a randomly generated community. The black lines represent linear fit to the data and the grey shading shows the $95 \%$ confidence interval.

Figure 3. Differences in bacterial production in relation to phylogenetic distance between communities for the active fraction (a) and the standing stock of bacteria (b). Differences in bacterial production are calculated as Euclidian distance between each pair of samples and phylogenetic distance as the mean distance between taxa in a community and their nearest phylogenetic neighbour in the second community. The grey shading shows the $95 \%$ confidence interval. The use of Bray-Curtis or Sorensen index for community similarity gave the same result (Figure S3). The grey shading shows the $95 \%$ confidence interval. 
Figure 4. Similarity in recurring bacterial assemblies and temporal trends in community

605

606

607

608

609

610

611

612

614

615

616

617

618

619

620

621

622

623

624

625

626

diversity. Panels (a) and (c) show correlograms of bacterial assemblies as a function of time lag for the active fraction (a) and the standing stock (c). Positive and negative correlation values show similar and dissimilar communities, respectively. Panels (b) and (d) show the seasonal trends of community diversity, expressed as the Shannon Index for the active fraction (b) and the standing stock (d). For the active fraction, the highest correlation values for community composition were for samples taken one year apart and the lowest for the communities separated by 6 months. The standing stock did not exhibit regular pattern of community similarity. As for community diversity, the active fraction did not show a significant regular seasonal pattern while the standing stock did (Figure S4).

4

5

8

9

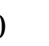
1 

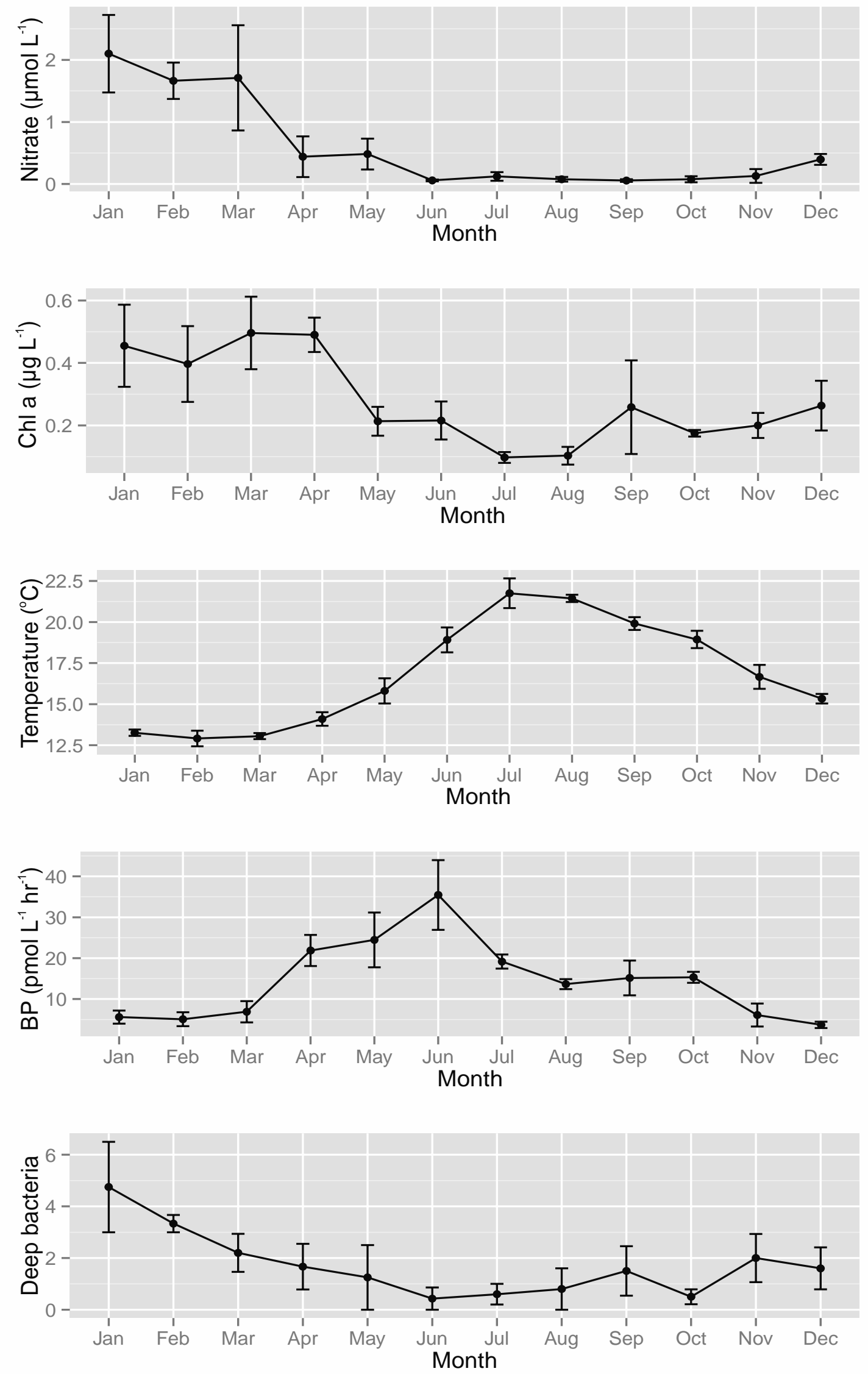

Figure 1 

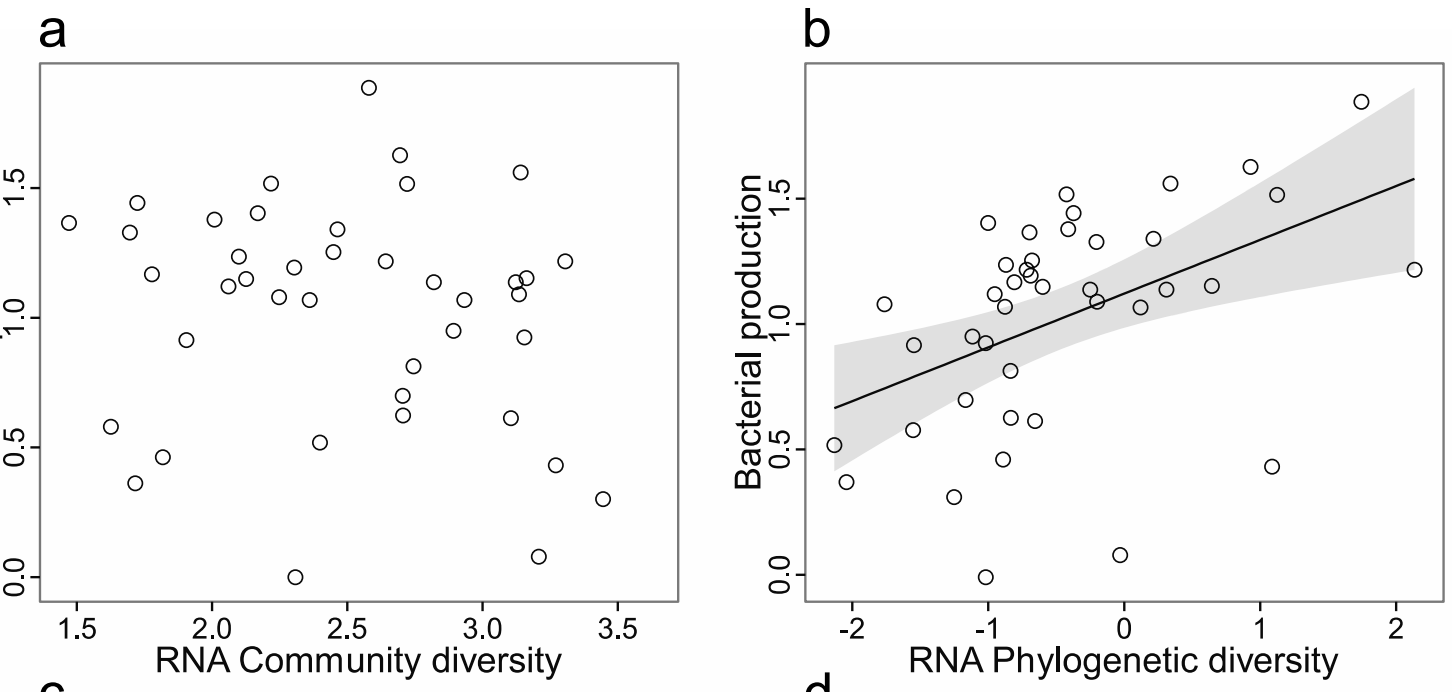

629
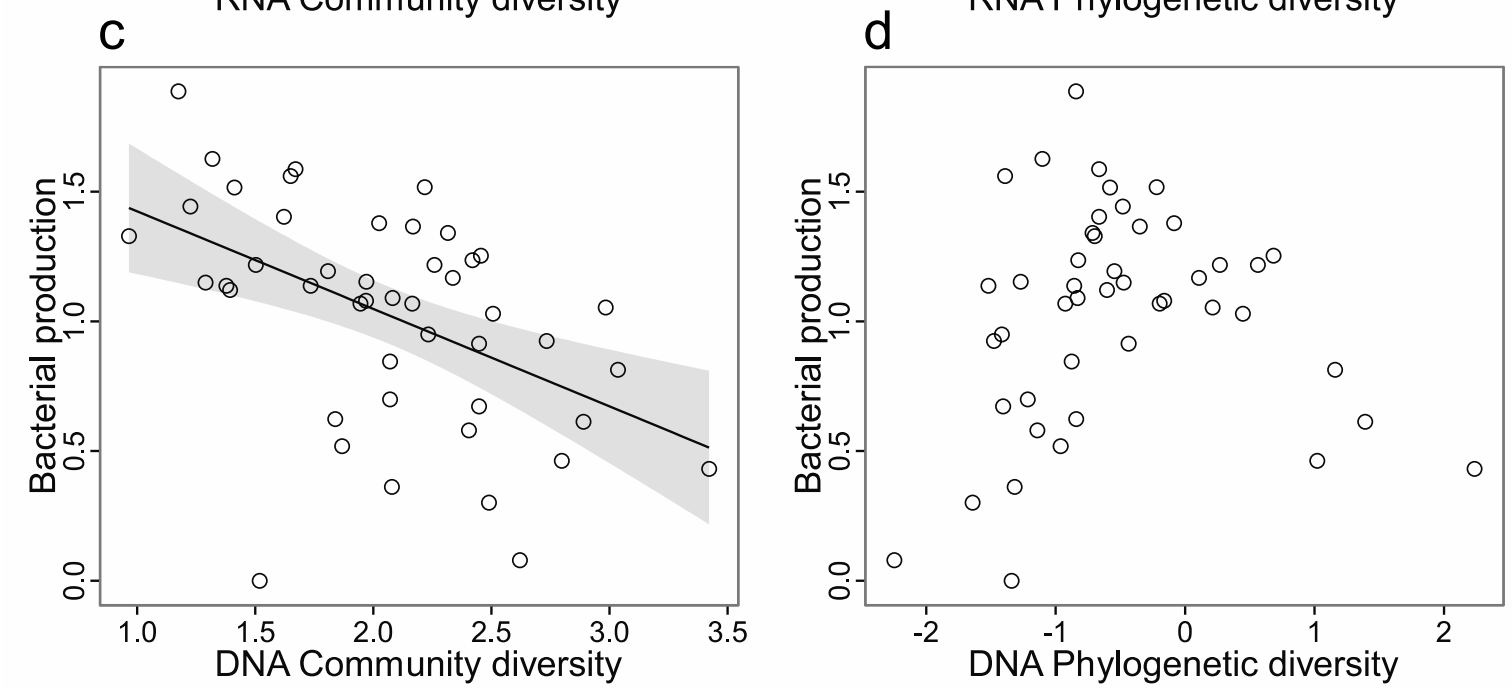

$630 \quad$ Figure 2

631 


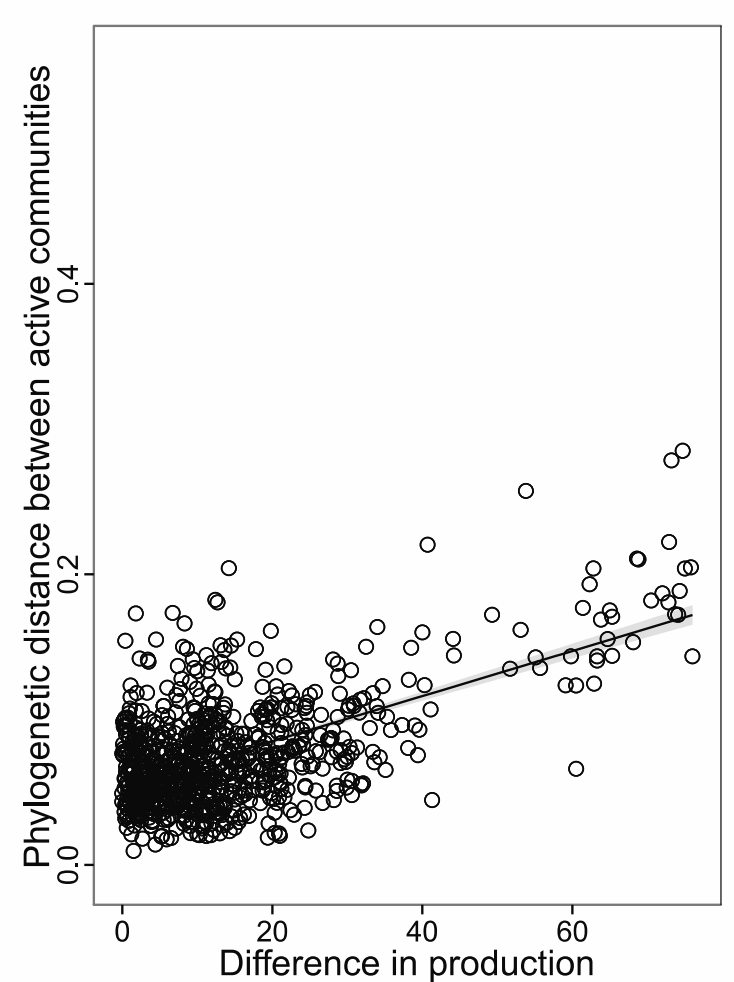

a

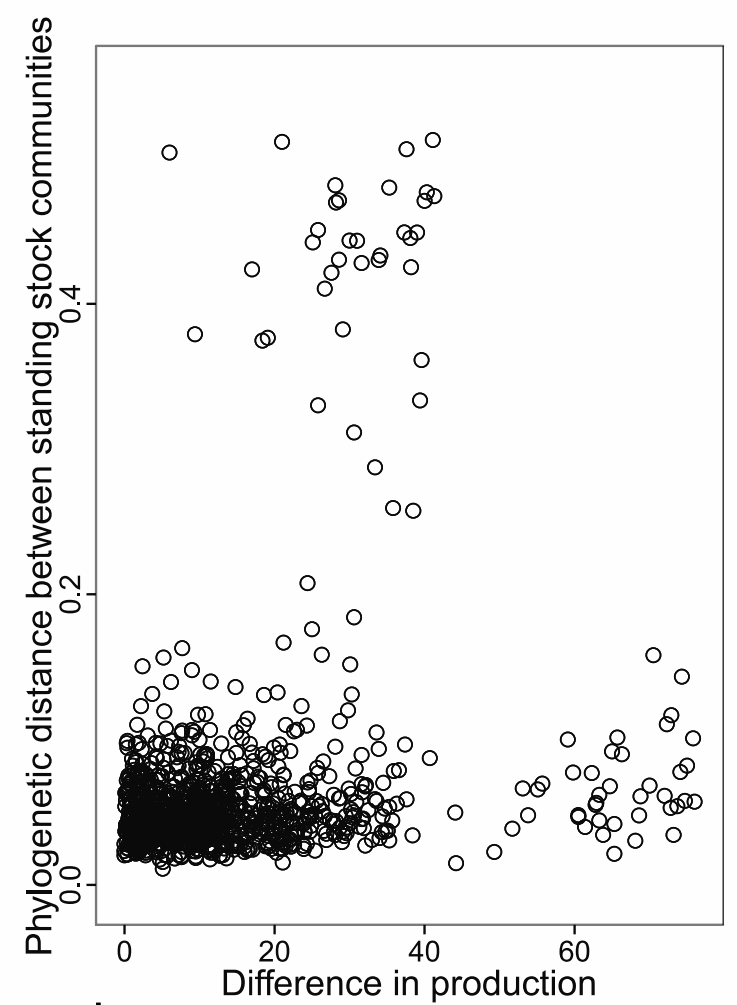

b

Figure 3 
660
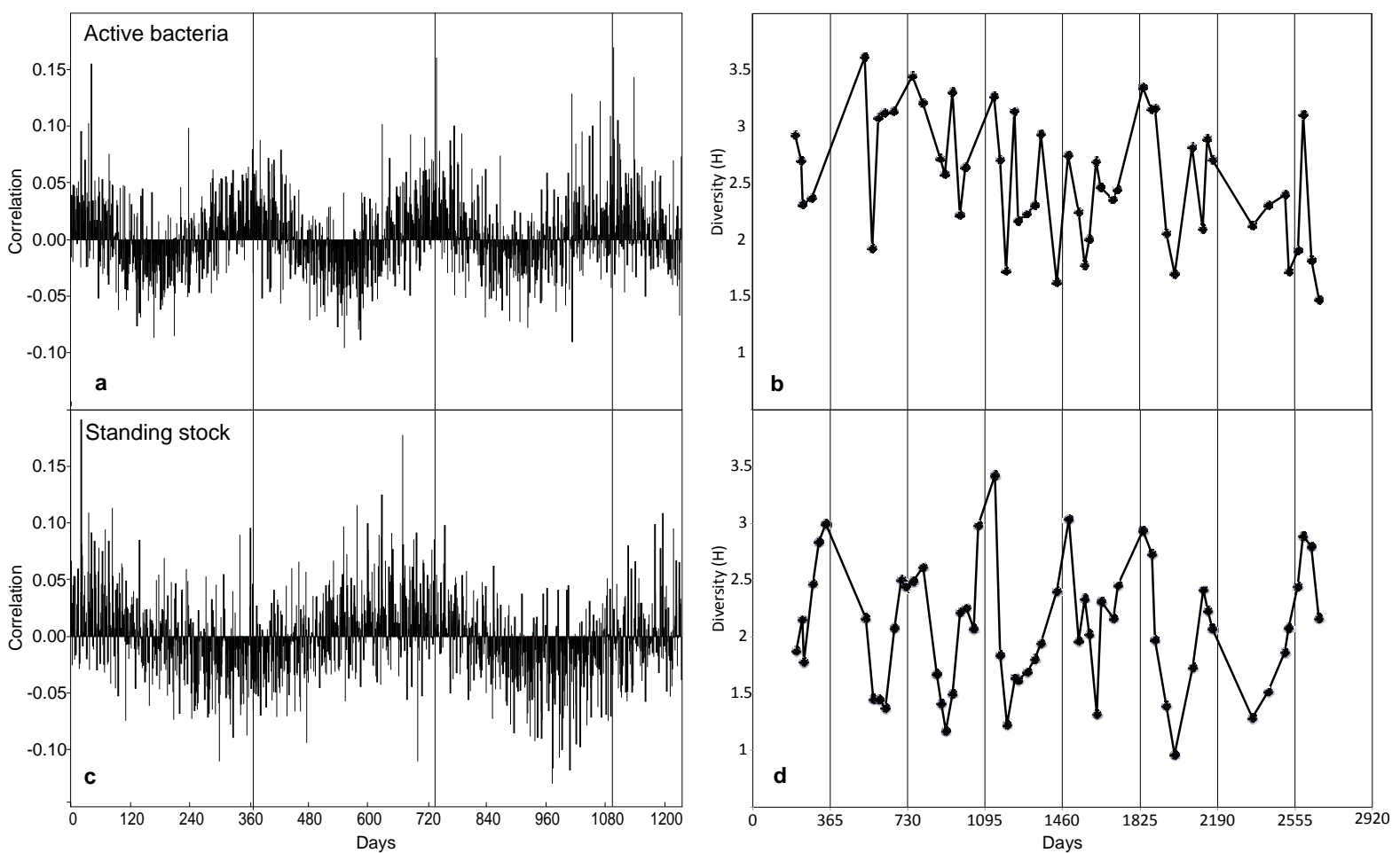

661

662 Figure 4 